\title{
Funduscopy: a forgotten art?
}

\author{
Elved Roberts, Rosemary Morgan, Debra King, Louis Clerkin
}

\begin{abstract}
Summary
Funduscopy is an integral part of the physical examination, especially in older patients in whom visual problems and systemic diseases affecting the fundi (eg, diabetes mellitus) are more common. We have assessed the views of hospital doctors to funduscopy via a questionnaire survey, reviewed the case notes to see whether or not funduscopy is carried out on older patients, and assessed the views of older patients on vision via a questionnaire survey. Review of the case notes showed only three of 100 patients had had funduscopy. Most patients reported a visual problem on specific enquiry. Whilst most hospital doctors believed funduscopy was important, many felt they had insufficient training in this procedure and felt their skills could be improved. We conclude that older patients are missing out on routine funduscopy. Hospital doctors should be aware that not all patients complain of visual problems and specific enquiry should be made. The issue of training and encouragement to perform funduscopy needs to be addressed before funduscopy becomes a forgotten art.
\end{abstract}

Keywords: funduscopy; visual impairment; audit

Examination of the ocular fundi is an integral part of physical examination. Life-threatening conditions such as accelerated hypertension, raised intracranial pressure, miliary tuberculosis, and melanoma may be revealed by ophthalmoscopy. Fundal examination may lead to the diagnosis of conditions such as glaucoma and retinal detachment. Inspection of the optic fundus may also help in the management of a number of systemic disorders, eg, diabetes mellitus and systemic lupus erythematosus. ${ }^{1}$

Funduscopy is especially important in older

Arrowe Park Hospital, Upton, Wirral, Merseyside L49 5PE, UK

Department of Geriatric Medicine

E Roberts

R Morgan

D King

Department of

Ophthalmology

L Clerkin

Correspondence to $\mathrm{Dr}$ Morgan

Accepted 4 January 1999 dition, we have looked at whether acute in-patients have had funduscopy perviews of hospital doctors in medicine on funduscopy and their ability to examine the ocular fundi and diagnose abnormalities present. As far as we are aware from a Medline search this has not been done before. In formed as part of their physical examination, and how frequently older patients report visual problems if specifically asked.

\section{Methods}

All senior and junior doctors (72) working in general and geriatric medicine in the same district general hospital were given a questionnaire (available from the authors); 41(57\%) responded, comprising 13 house officers, 12 senior house officers, five specialist registrars, one staff-grade and 10 consultants). Replies were anonymous so non-responders could not be contacted. The same 72 hospital doctors were invited to view four slides (showing a fundal abnormality) and to examine four patients (previously reviewed and diagnosed by a consultant ophthalmologist) with an ophthalmoscope, and state the diagnosis in each case. Only 14 doctors participated in performing the funduscopy and making a diagnosis.

One hundred elderly in-patients (mean age 82 years, range $72-92,76 \%$ female) in a district general hospital, were interviewed by a doctor not involved in their medical care. All patients scored $8 / 10$ or more on an abbreviated mental test score, ${ }^{3}$ and were fully recovered from their acute illness. A questionnaire was administered and the responses recorded. The case notes of the same 100 patients were audited using a standardised proforma.

The study was approved by the Wirral district's ethics committee.

\section{Results}

All doctors surveyed felt funduscopy was important but only eight felt it should be performed on all patients and only three doctors routinely perform funduscopy. Half (49\%) would perform funduscopy for patients with diabetes mellitus, hypertension, visual impairment, and neurological symptoms. The more senior doctors were more likely to have performed more funduscopies in the preceding 3 months than junior doctors (Cuzick's test for trend 2-tail $\mathrm{p}=0.0005)$. Only $18(44 \%)$ doctors were confident in performing funduscopy, $34(83 \%)$ felt they would benefit from more training, $30(73 \%)$ had had insufficient training in funduscopy and most (97\%) believed their funduscopy skills could be improved. All 41 do not routinely dilate the pupil before funduscopy for a number of reasons: insufficient time (19), concern at inducing glaucoma (10), don't know how to dilate (nine), and don't think it's necessary 
Table Performance of the 14 physicians who examined the selected slides and patients

\begin{tabular}{ll}
\hline Test & $\begin{array}{l}\text { No correct } \\
(\%)\end{array}$ \\
\hline $\begin{array}{l}\text { Slides of ocular fundi } \\
\text { Papillodema }\end{array}$ & $10(71)$ \\
$\begin{array}{l}\text { Hypertensive retinopathy } \\
\text { Proliferative diabetic retinopathy }\end{array}$ & $12(86)$ \\
Maculopathy with photocoagulation scars & $12(86)$ \\
$\begin{array}{l}\text { Ocular fundi examined by ophthalmoscope } \\
\text { Retinitis pigmentosa }\end{array}$ & $11(79)$ \\
$\begin{array}{l}\text { Papillodema } \\
\text { Diabetic maculopathy } \\
\text { Diabetic proliferative retinopathy with } \\
\quad \text { widespread photocoagulation therapy }\end{array}$ & $3(21)$ \\
\hline
\end{tabular}

(three). Reasons given for not performing funduscopy included: insufficient time (12), not skilled enough (nine), lack of available equipment (four), and not useful (one).

A correct diagnosis was more likely to be made from looking at a slide than from funduscopy, suggesting a lack of skill in funduscopy technique (table).

Review of 100 case notes showed that only three patients had had funduscopy documented. All these patients had diabetes mellitus. Nine patients with diabetes and 35 with hypertension had no funduscopy recorded. The majority of patients (97) reported a visual defect ranging from glasses for reading (28), cataracts (22), blurred vision (18), myopia (15), hyperopia (six), wavy lines (three), and visual problem of uncertain nature (five).

Half $(49 \%)$ were concerned about their eyesight, but only 13 patients had been asked about visual problems by their hospital doctor; three of these patients recalled the doctor examining their eyes. The mean time since review by an optician was 3.5 years. Only nine patients were deterred from going to the optician by having to pay.

\section{Discussion}

Visual problems are common in older people. In this study the majority of patients had some type of visual impairment. On enquiry, some patients were experiencing specific problems but few had mentioned this to their doctor. There may be several reasons for this underreporting, including decreased expectations in old age and a belief that nothing can be done, ${ }^{4}$ as well as lack of enquiry by medical staff. Of concern is that only $23 \%$ of patients who specifically reported a visual problem could recall having their eyes examined (confirmed by case note review). Many patients (49\%) were concerned about their eyesight. Since most are not deterred from going to the optician by having to pay and there is some concern about screening in the community by general practitioners (of patients over 75 years), ${ }^{5}$ one possible solution is to encourage older people to go to the optician on a regular basis (say, once every 2 years). There was a wide variation in this study in the frequency of going to the optician (some patients going on a regular basis whilst some had never been). Since some of the patients who had never seen an optician were not deterred by the prospect of having to pay, there may be a role for health education, although there may be other explanations for not going to the optician (eg, poor mobility). Doctors should be aware that not all older patients complain of visual problems and specific enquiry should be made.

Although only half of the doctors said they would perform funduscopy for patients with diabetes mellitus, hypertension, visual impairment, and neurological symptoms, most elderly patients with these conditions had not had funduscopy performed.

Participation in looking at the slides and fundi was poor, even though doctors were reassured that the results would be anonymous. There are probably several reasons for this but it may reflect apprehension by some doctors regarding their skill in funduscopy. It is unlikely that those who did not participate are any better at interpretation than those who did. Doctors were more likely to diagnose a fundal abnormality correctly from a slide than from actual funduscopy, which suggests that it is a problem with technique rather than lack of knowledge. Unfortunately, the numbers participating were too small to draw any significant conclusion.

There are multiple reasons why funduscopy is not done; in this study the main reason given was insufficient time. Increasing acute admissions to hospital with increasing demands on hospital doctor time may lead to omission of funduscopy, once an integral part of the physical examination. This may, in turn, have an impact on training, not to mention patient care, ultimately resulting in a generation of doctors unskilled in this procedure and funduscopy becoming a forgotten art known only to the ophthalmologists.

We believe that funduscopy should remain an integral part of the physical examination. It is a skill acquired through training and practise. Training in this technique should be considered part of general professional training in medicine and should be encouraged by physicians. With increasing cross-cover, one option would be to involve senior house officers on a medical rotation with those in ophthalmology. An alternative option would be to provide protected teaching for junior medical staff from an ophthalmologist or senior physician skilled in funduscopy. Senior physicians should not be complacent that their junior staff are learning funduscopy the same way that they did, ie, by performing it. Clinical medicine is changing with ever-increasing pressure on time to see more and more acute patients. Junior doctors may well feel that they do not have time to perform funduscopy and if senior doctors fail to comment, this maybe interpreted as tacit agreement that funduscopy is irrelevant.

In conclusion, few older patients are having funduscopy performed as part of the routine physical examination and many doctors feel their training in funduscopy has been inadequate and their skill in this technique could be improved. 
We acknowledge the help of Dr CJ Turnbull with the statistical analysis, and Dr S Prasad for help with provision of photographic slides. We would also like to thank the doctors and patients who made this study possible.

1 Macleod J, Munro J. The use of the ophthalmoscope. In: Macleod J, Munro J, eds. Clinical examination. UK: Churchill Livingstone, 1986; pp 408-20.

2 Wormald RP, Wright LA, Courtney P, Beaumont B, Haines AP. Visual problems in the elderly population and implications for services. BMF 1992;304:1226-9.

3 Qureshi KN, Hodkinson HM. Evaluation of a 10 question mental test in the institutionalised elderly. Age Ageing 1974;

3:152-7.
4 Landes R, Popay J. "My sight is poor but I'm getting on now". The health and social care needs of older people with visual problems. Health Soc Care 1993;1:325-35.

5 Smeeth L, Iliffe S. Effectiveness of screening older people for impaired vision in community setting: systematic review of evidence from randomised controlled trials. $B M F$ 1998;316:660-3.

\section{Medical Anniversary}

\section{Sir Arthur Conan Doyle, 22 May 1959}

(Sir) Arthur Conan Doyle (1859-1930) was born in Edinburgh, UK, where he was later to be awarded MD for his thesis on tabes dorsalis. He first practised in Southsea and then transformed himself into an ophthalmologist, neurologist, athlete, war correspondent, spiritualist, prolific writer and humanitarian. King Edward VII conferred a knighthood in 1902, not for creating Sherlock Holmes but for his involvement in the Boer War as physician, and as a war correspondent justifying British involvement in South Africa. But everybody worldwide will remember him as the creator of Sherlock Holmes, Dr Watson and Moriarty. When he died in 1930, it needed the huge Albert Hall for his memorial service. A tombstone for him and his wife stands at All Saints Church, Minstead, Hampshire. It bears the inscription "Steel true, Blade straight, Patriot, Physician, Man of Letters". — DG Fames 